horne and P. Weiss. Volumes 7 and 8 were edited by A.W. Burkes. The paragraphs in these volumes were not chronologically ordered by the dates on which Peirce wrote them and some were taken from Peirce's unpublished manuscripts located in the Widner Library at Harvard.

Ratner, Joseph, ed. 1939. Intelligence in the Modern World; John Dewey's Philosophy. New York: The Modern Library.

Veblen, Thorstein. 1898. "Why Is Economics Not An Evolutionary Science?" Quarterly Journal of Economics 12 (July): 373-9.

1898-1899. "The Instinct of Workmanship and the Irksomeness of Labor." The American Journal of Sociology 4 (July 1898-May 1899): 197-201.

1905-1906. "The Place of Science in Modern Civilization." The American Journal of Sociology 11 (July 1905-May 1906): 585-609. Sons.

1904. The Theory of Business Enterprise. New York: Charles Scribner's

Weiner, Philip. 1949. Evolution and the Founders of Pragmatism. Cambridge: Harvard University Press.

\title{
Professor Tinbergen's Economics: A Comment on Dopfer
}

Since every scientist is interested in a review of his own product, I read Professor Kurt Dopfer's review article with great interest. If a review assumes the form of a review article its interest is larger even. In his article Professor Dopfer refers to the well-known discussion about my League of Nations econometric work between Lord J. M. Keynes and myself in the early years of "model building." Last year, in Amsterdam, the fifty-year anniversary of the first model (of the Dutch economy) was celebrated. Dopfer finishes his article by quoting Keynes's kind personal words and I want to thank him for this gesture. But the main impression left is that our approaches to econometric model building are very different indeed. The problems I try to solve are, let me say, much more down to earth than Dopfer's problems, which are situated in the field of the philosophy of science. This is not my area of specialization and hence not the area covered by my book. So it is only in a few isolated sub-areas that we meet. One of his statements is that I treat economic science as a "branch of classical mechanics." My way of describing the position of these two sciences would be that both use the method of logical deduction and verifying the results by empirical testing. As a consequence of my training in physics I consider these two elements as the necessary components of any complete science. 
Another point where we meet and disagree is the approximation of functional relationships by linear relations. To me this is not an issue of fundamental importance: I am prepared to use non-linear relations wherever needed. But for small variations in variables linearization is a good approximation and an easy simplification.

A third point where we meet in disagreement is the role of gravity in physics. It is not such a central role; many chapters of physics (sound, light, electromagnetism, for instance) can be dealt with without gravity. Our distance becomes larger where Professor Dopfer wants me to be more explicit about "what of my econometric work relies on wellestablished theoretical foundations and what lacks such 'qualitative' properties." My reaction here is a request to him to list the subjects of my book that suffer from one or both of the "fallacies" he identifies.

One clarification I want to offer is that the same economic variable (or phenomenon) may be an unknown in one problem and a datum in another. Typically we may make the general distinction between analytical (or explanatory) and policy (or planning) problems, in which target variables and instrument variables change their role.

The preceding and several other aspects have made Dopfer's article an article about my work, but hardly a review of the 1985 book. In a review I hoped to find the reviewer's judgment of some of the innovations I thought I had offered. Here I shall be quite explicit in claiming a number of innovations for each chapter.

Chapter 1: A remarkably low marginal productivity of managers is found.

Chapter 2: A correction of the inventive method developed by Peter Gottschalk to estimate production functions with a large number of production factors.

Chapter 3: An application of the concept of "non-essential" production factors to the problems of schooling: how can schooling affect total production and income distribution?

Chapter 4: Introduction of the concept of counterproduction in order to better describe reality; what types of counterproduction can be eliminated?

Chapter 5: Not all collective goods are perfectly collective and this implies the necessity to introduce a type of goods called part-collective.

Chapter 6: Lacunae in the field of econometric estimation of production functions are listed. (In passing, I propose to replace the concept of "disembodied technological change" with "unembodied.") 
Chapter 7: A discussion with Eckhard Wegner on the explanation of income formation. Whereas Wegner's proposal is very attractive, it is not the only possible correction of my original model.

Chapter 8: The impact of "occupational status" (0) on income formation-proven statistically to exist-may be explained in different ways. These alternative explanations are identified and called the "effort aspect" and the "psychological income aspect." The positive impact of $O$ on income supports the effort aspect. The size of this impact suggests which part of income variation can be ascribed to differences in effort made. These differences are among the factors that produce "justifiable" income differences. The author mentions the "heroic accumulation of assumptions" used in this chapter.

Chapter 9: Is an attempt to identify the most important determinants of manager incomes, distinguishing between demand and supply factors.

Chapter 10: Contains an attempt to define and subsequently to measure, an equitable income distribution.

Chapter 11: Addresses the controversial question whether welfare (or utility), a central concept in economic science, is or is not measurable. The majority of today's economists deny its measurability, but an increasing number is opting in favor of measurability.

Chapter 12: Deals with the allocation of workers with different levels of schooling and other qualifications over the jobs to be filled and requiring different qualifications.

Chapter 13: Further pursues the definition and measurement of welfare, lists some neglected determinants.

Chapter 14: Discusses by what institutions and policy instruments welfare of a given community over a given period can be maximized. This is the hard core of the book, namely the problem of the optimum social order. It may be seen as the author's ambitious attempt to substitute a scientific approach for an intuitive political choice (on pages 155 and 157 some errors have crept in, on which information can be obtained from the author).

Chapter 15: Enters in some more detail with regard to the tax system.

Chapter 16: Is an answer to critical remarks made by Professor 
Robert H. Haveman on the educational sector in a previous version of the optimal social order.

Chapter 17: Addresses the question how to define and how to attain an order that could be called "socialist."

Chapter 18: Deals with the topical subject of coexistence of countries with differing social orders. In a review of my book, listing and commenting upon some of these proposed solutions of the problems could have been anticipated.

Jan Tinbergen

The author is emeritus professor of development planning, Erasmus University of Rotterdam.

\section{Reply To Jan Tinbergen}

Professor Tinbergen refers in his comment to three points "Where we meet and disagree." He also mentions a "number of innovations" he made in his 1985 book.

My article was, as stated at the outset, intended as a review of some of the essential features of his work; it was indeed "hardly a review of the 1985 book." I apologize for having failed to inform the reader fully about the innovations listed in Tinbergen's comment, and I hasten to add that I wish to recommend warmly his book to the reader. In the following, I will confine my reply to issues that lie on the ground "where we meet," and where his comments reconfirm our disagreement.

First, Professor Tinbergen mentions that classical mechanics is a science that applies logical deduction and empirical testing, and that for that reason he feels committed to it. There can be little disagreement on the desirability of such commitment. Most modern sciences, even psychology, apply in some way or other deductive schemes in a logically consistent way, and they attempt to test hypotheses. Professor Tinbergen could have referred to virtually any other modern science (besides physics) to find such methodological support. The critical point I have tried to make refers to the theoretical substance that is imported from physics into economics. It is, hence, not a methodological or "philosophical" issue, but an eminently theoretical one. Admittedly, the reasoning is not "down to earth" but refers to the level of basic theoretical assumptions that support the deductive scheme applied for 